\title{
El Gobierno de la Familia
}

\author{
por el Dr. SANTORO PASSARELII, \\ Catedrático de la Universidad de Roma
}

\section{I.-El Orden natural de la familia.}

"Una sola razón me lleva a escribir estas líneas: es, en efecto, porque confío en que otros padres las leerón y que emplearán un método educativo completamente distinto con relación a sus hijos. Sacando provecho de nuestros errores, lograrón, tal vez, detener la ola de violencia y de rebeldía de los adolescentes.

"Sí, condenad a Christopher por su tremendo crimen, pero condenad también a los padres como nosotros que, por haber prodigado su afecto $\alpha$ este niño, por haberle evitado los castigos y por haber escuchado todos las habladurías sobre la libertad necesaria de los hijos, somos aún más culpobles que ellos mismos".

Este grito de dolor de un desgraciado padre inglés, cuyo hijo no es otro sino el asesino Christopher Craig, de 16 años, que llegó hasta mí, cuando ya pensaba en "el gobierno de la familia en el seno de la sociedad contemporónea", tema de mi informe a este Congreso, me parece que debe ser la introducción ideal para el presente irabajo. Llama nuestra atención sobre el punto esencial: a saber que se trata no solamente aquí del orden familiar y de la autoridad marital y paterna, sino también de preservar a la persona humana de la muerte $y$ del crimen.

La formilia misma no representa un fin en sí: es el instrumento indispensable del bien de la persona, de los bienes esenciales y fundamentales de la persona, de toãas las personas que viven en el seno de la familia y de la sociedad. Como lo ha declarado recientemente el Papa Pio XI, existe para todo cristiano una regla que determina con certidumbre el alcance de los derechos y de los deberes de la familia en la comunidad del Estado: "La familia no existe para la Sociedad; es la Sociedad la que existe para la familia" (discurso pronunciado onte un grupo de padres de familia el 18 de Setiembre de 1951). Podemos, por consiguiente, agregar, ciemne en el mismo sentido, que, a su vez, la familia es para la persona. Pero, 
como las personas, por medio de las familias, viven en la comunidad del Estado ("per communitatem domesticam civilem ineunt ac participant societatem", Rerum Novarum, 15 de Mayo de 1891), se comprende por qué, con razón, el mismo Papa ha subrayado, inmediatamente después, que el Estado debe respetar los derechos de la persona y de la familia "aún, por así decirlo, en virtud del instinto de conservación".

Lo que se pide al Estado y al derecho del Estado, no es que promueva, que establezca el orden en las familias - puesto que en esta materia el derecho sería incapaz de hacerlo-, se le pide, por el contrario, que respete $\mathrm{y}$ secunde, si fuere necesario, por medio de nuevas instituciones auxiliares, el orden natural de la familia, es decir el orden que la fomilia ha sabido darse según el orden divino.

Puesto que, sin este orden, la familia no se mantiene y desaparece, y como sin la familia lo mismo sucede con el Estado - no ha logrado $y$ jamás logrará susituirse él mismo a la familia o a sustituirle otra institución - deberemos esperar, con justa razón, que el Estado respete ese orden naiural, y que ejerza una acción directa para protegerlo frente a algunas tendencias actuales dispendiosas, aun cuando fuere solamente por la razón práctica y primordial de la conservación, propia de todo organismo viíal. ¿Qué sucede por el contrario?

He aquí que en Francia, en este país que nos acoge, cuna de tradiciones ícmiliares tan luminosas, la comisión de reforma del código civil francés examina una reforma de las relaciones entre esposos, y entre padres e hijos. Colocada bajo el noble signo de la iqualdad de los esposos en el seno de la familia, si llegara a realizarse transformaría no solamente a la familia francesa en una "familia sin jefe", como se ha dicho, sino que termincría sencillamente con la destrucción de la familia; es cierto, en efecto, que, como cualquier otro organismo y más que cualquier otro, la familia, por su estructura peculiar, no puede vivir sin un jefe. En nuestra sociedad, la familia, pequeña y reducida, proprio iure, constituída por padres e hijos, es la única que, en adelante, sobrevive. $Y$ es de ella que nos ocupamos y nos preocupamos. Cualesquiera que sean los móviles y los fines de los reformadores, esa reforma no podría tampoco tener oiro resultado sino la desintegración de esta familia sobreviviente, ya amenazada de tantas. maneras.

Suponemos y comprendemos, por consiguiente, que esos proyectos de reforma han sugerido a nuestros amigos famceses colocar como priner temc de este Congreso Internacional de Juristas Católicos el "Gobierno de la Familia". Sobre un gobiemo apropiado descansa la existencia de la familia: pues bien, si, por la razón expuesta más arriba, el problemce es mós candente para los franceses, no es menos interesante para los demós pcísé represeniados aquí. En efecto, el problema del gobiemo de la familia constituye un problema actual que preocupa a todos los países de civilización cristiona, por varias circunstancias y según otros motivos, como lo confirman los informes nacionales que sirven de base para este informe. 


\section{II.-Gobierno de la familia e igualdad de los esposos.}

¿Podemos plantear la cuestión fundomental del gobierno de la familia en los siguientes términos: ¿existe o debe existir un jeie, o los dos esposos son iguales o deben serlo?

No podemos dar respuesta a esta pregunta sinó de una manera, es decir que, debe existir un jefe, el esposo, y que los esposos deben ser iguales: ésto según la enseñanza de la Iglesia y el desarrollo racional de las instituciones, como lo reconocen las legislaciones lás más avanzadas.

La enseñanza de la Iglesia es precisa, si se desea recogerla en las más altas y recientes manifestaciones de su doctrina, sin pegarse c: la letra de ciertas definiciones de antiguos doctores, sacando de ellas su verdadero y eterno espíritu. Ya la Encíclica Arcanum (10 de febrero de 1880) precisaba que la mujer "no debe someterse y obedecer a su esposo como una sierva, sinó como una compañera, es decir de monera que el sometimiento no sea separado del honor y de la dignidad, deseando de los dos esposos "uno representando la imagen de Cristo, el otro la de la Iglesia", "que la caridad divina sea la moderadora perpétua de sus deberes". Estos argumentos han sido recordados en la Encíclica Casti Connubi (31 de diciembre de 1930): allí queda especificado que el sometimiento de la mujer "no niega ni restringe la libertad que, con pleno derecho, tiene tanto a causa de la nobleza de la persona humana, cuanto por su muy noble función de esposa, de madre y de compañera; no la obliga a someterse a todos los caprichos del hombre, poco conformes con la razón o la dignidad de la esposa; por fin, no admite que la mujer sea puesta en el mismo nivel que las personas designadas en el derecho como incapaces, a quienes, por falta de madurez de juicio o por causa de su inexperiencia de las cosas humanas, no se desea otorgar el libre ejercicio de sus derechos; pero defiende esa libertad exagerada que no se preocupa del bien de la familia; prohibe que del cuerpo de esa familia se separe el corazón del jefe, con gran desmedro del cuerpo entero y con el peligro de ruina próxima; y tal como el hombre detiene la primacía del gobierno, csí la mujer puede y debe atribuirse personalmente la primacía del amor". Y la Encíclica precisa: "en cuanto a la consecuente intensidad y modo de este sometimiento de la mujer al marido, éstos pueden variar según las personas, los lugares y los tiempos; si, por el contrario, el hombre no cumple con su deber, toca a la mujer reemplazarlo en la dirección de la familia". La Encíclica concluye: "Pero en ningún tiempo, ni en ningún lugar es permitido trastomar y lesionar la estructura esencial de la misma familia y su ley divina sólidamente establecida".

Este es el punto inquebrantable sobre el cual deben descansar y descansan generalmente hasta ahora, las leyes de los países cristionos, como lo hacen notar los informes nacionales presentados a este Congreso. Del Líbano a Holanda, de España a Suiza, el grado y el modo de sujeción de la mujer al marido varían según las condiciones sociales y las tradicio nes; sin embargo, lo. estructura esencial de la familia según la ley divina es respetada en las diferentes legislaciones. Como lo veremos, son las costumbres y la opinión públiea, las que señalan desviaciones angustiosas y 
es deber de cada uno y del Esiado, también por su propio interés, no ceder sino resistir para evitar el daño.

\section{III.-Funciones $y$ órganos de la tamilia.}

La oposición entre gobiemo del marido e igualdad de los esposos es aparente, puesto que ninguna desigualdad verdadera puede resultar de la coordinación necesaria de las funciones que comprenden a los diferentes sujetos que actúan en farvor de un organismo denuro del mismo. Y así como no habría ningún motivo para atribuir funciones idénticas a varios organismos sin establecer un órgano destinado al control de las diferentes funciones de cualquier organización, a nombre de la igualdad de las personas a las cuales están confiadas las diferentes funciones, es por lo mismo absurdo, a nombre de la igualdad de los esposos, atribuir las mismas funciones conjuntamenté al marido y a la mujer, sin dar un jefe a la familia. Si se procede como se debe proceder, no a base de les principios del derecho subjetivo y del deber correspondiente, sinó con funciones $y$ organismos necesarios a la vida del organismo, merced a los cuales el poder $y$ la sujeción correspondientes resultan secundarios, bien puede verse que la igualdad no se halla en discusión. La Igualdad no puede significar que todos los sujetos desempeñen las mismas funciones. La igualdad solo exige que una posición incompatible con su libertad y su dignidad no resulte para ninguno de los sujetos dentro de la organización; que la preposición y la sujeción se mantengan exactamente dentro de los límites señalados por las funciones; que éstas se hallen repartidas según las diferentes aptitudes y posibilidades de los sujetos.

\section{IV.-Evolución del gobierno de la familia.}

Algunas de las legislaciones más avanzadas señalan el camino que se ha podido recorrer, dejando al mismo tiempo entrever, aún entre las reformas contempladas, cuanto se puede todavía recorrer, desde las rígidas $\mathrm{y}$ antiguas autoridades familiares, hasta configuraciones ágiles y dúctiles de cuioridades que consienten a la mujer -como es justo y normal- una elevación cada vez mayor de su situación dentro de la familia; y todo aquello sin disminuir el principio fundamental de la unidad de gobierno de la familia y de la atribución mormal al marido de las funciønes de jefe, según sus aptitudes y posibilidades.

\section{Relaciones personales.}

El deber de obediencia de la mujer ha desaparecido en casi todas partes, en su definición textual, de las legislaciones contemporáneas, y parece igualmente que el deber de proiección del marido se halle correlativamente en vías de desaparecer, ya que se cree ver en él un motivo de humillación para la mujer. Pero, en general, el concepto según el cual el marido es el jefe de la familia permonece firme en los países de civilizcción cristiana, lo que da lugar a algunas prerrogativas esenciales, indispensables para el cumplimiento de su tarea. 
El marido es el jefe de la farmilia, pero la mujer colabora con él y en todas circunstoncias, lo sustituye en el cumplimiento de esta función, como lo prevee el texto actual del Código civil francés (art. 213). El Código suizo (art. 161), establece que le debe ayuda y consejo para la prosperidad común.

De la idea de función resulta, aún allí donde la ley no lo establece de manera precisa - como en el Código Peruano de 1936 (art. 136)- que todo abuso puede ser reprimido por vía judicial, y la primera persona que legítimamente puede solicitar la represión del abuso es naturalmente la mujer.

Puesto que se trata del reparto de funciones, es natural que zomprenden las que son propias de la mujer $y$ que le corresponden por sus aptitudes y posibilidades, como la dirección y la representación para los asuntos domésticos corrientes. Poder doméstico propio de la mujer encargada de la casa, de grandes alcances, aún cuando esté necesariamente subordinada al gobierno del marido. Este poder se ejerce en la realidad familiar de todos los países, aún cuando diferentes legislaciones de tipo latino no lo preveen todavía, por lo menos de manera expresa, tal, por ejemplo, el reciente código civil italiano. Por el contrario está previsto bajo sus dos aspectos interno y externo por el código civil alemán (arts. 1356/ 1357), y estó precisado en su estructura y en sus efectos especialmente por el código civil suizo (arts. 161, 163, 164), así como por el texto actual del código civil francés (art. 220).

Las legislaciones que, después de haber reconocido al marido su calidad de jefe de la familia, establecen que el ejercicio de la cutoridad sobre los hijos menores es común al padre y a la madre, demuestran que paro dar un jefe a la familia. no es necesario preferir al marido para el ejercicio de la patria potestad, que algunas legislaciones llaman más propiomente autoridad de los padres. Basia que, a falta de acuerdo, la decisión corresponda al marido, decisión definitiva si se traia de una evaluación de convivencia, pero sujeta al control del juez o de órcr autoridad pública, con el fin de adoptar diferentes scluciones previstas por la ley, cuando se transforma en abuso. Es el principio estchlecido por el Código civil suizo (arts. 274, 284, 285) y adoptado después por otras legislaciones, como el actual Código peruano (art. 391) y el Código holandés (art. 356).

\section{Relaciones patrimoniales.}

$E_{\mathfrak{s}}$, sin embargo, en el campo patrimonial, que el camino recorrido por la mujer es el más largo, y esta evolución está lejos de haber llegado a su término.

En muchos países, la autorización marital ha dejado de ser necesaria para los actos relacionados con la libre disposición de los bienes de la mujer. Esta es, desde luego, una institución mal entendida, por el mismo hecho de que no es útil a la unidad del gobiemo aún patrimenial de lá familia y por el hecho que supone como fundamento la incapacidad de la mujer en la administración de sus propios intereses frente al marido. Su descaparición no debería haber permitido y no debería, tormpoco, permitir a la mujer comprometer libremente su actividad personal, en perjuicio de 
sus deberes conyugales y familiares, como sucede cuando la abolición de Ic: cutorización marital no se sustituye con un control de lus mencionados cicios.

Al abolir la autorización marital, se está realizando, como es natural, en vista de su estrecha relación, una profunda evolución de los regímenes tradicionales del matrimonio.

Los regímenes traciicionales de comunidad $y$ el régimen dotal están cediendo el lugar a regímenes nuevos cuya característica consiste en no colocar necesariamente los bienes de la mujer, propios o adquiridos, en manos del marido. Lo que es indispensable -es lo que, por otra parte, se efectúa bajo el régimen de la separación de bienes- es que la mujer participe, proporcionalmente $\alpha$ sus ingresos, $\alpha$ las cargas del matrimonio, aún si éstas recaen principalmente en el marido (art. 214 del Código francés, por ejsmplo), como debe ser, yœ que éste deber fundamental corresponde a su situación de jefe. Pero, el régimen de la separación de bienes, ccida vez más en boga, si bien asegura a la mujer la libre disposición de sus bienes, deja de kado un hecho de importancia capital, a saber la unión y la colaboración conyugal que se realizan generalmente también en el aspecto matrimonial. Si no se desea que el matrimonio cree trabas a la libre disposición de los bienes por el cónyuge a quien pertenecen, y principalmente para la mujer, en lo que se refiere de manera especial a las rentas que provienen de su trabajo profesional, una unión íntima y una colabora. ción que ha durado a veces largos años, como la que existe entre cónyuges, debe, por otra parte, ser objeto de una compensación por lo menos cuando el matrimonio llega a disolverse.

Esto origina un nuevo sistema de administración de los bienes de los esposos que, en el rigor de los términos, no se puede llamar régimen, ya que no halla aplicación durante el matrimonio. según el cual los bienes -o solamente los adquiridos durante el matrimonio- de cada uno de los cónyuges permanecen, durante el matrimonio, a disposición del cónyuge a quien pertenecen, soportando exclusivamente sus deudas, pero que se repar. tan, por partes iguales, entre los cónyuges o sus herederos al disolverse el matrimonio.

Esta participación diferida, introducida primero en las leyes escandinavas, está ganando terreno. Ha sido adoptada por el código peruano en cuanto a los ingresos provenientes del trabajo de la mujer (art. 206). Se trata de introducinla en Francia desde 1932, bajo la forma de la participación en los ganaciales. La idea que la inspiró fué expuesta de la siguiente manera: "cada uno es dueño de su patrimonio durante el matrimonio; al disolverse éste solamente, se procederá a la liquidación de las gananciales y se pagarán". Es la reglamentación de las relaciones matrimoniales entre cónyuges que también, parece ser preferida, en la reforma del código civil holandés y ha sido adoptada en el proyecto del Gobiemo alemán.

Para nosotros, nos parece que esta participación diferida de los cónyuges conciliaría la exigencia de la libre disponibilidad de sus bienes y los caracteres fundamentales de la asociación conyugal, de manera 
especial, en cuanto a la contribución de la mujer al patrimonio de la familia, que es muchas veces de extraordinaria importancia.

A propósito de esta contribución. desearíomos aún que se reconozca a lor mujer, al disolverse el matrimonio y cuando lo justificasen las circunstancias. un beneficio especial, como el previsto por el actual código civil suizo (art. 214), y análogo a la antigua tertia colaborationis.

Sería deseable, por otra parte, consagrar un reconocimiento más amplio y más preciso que el que figura generalmente en nuestras leyes, de la deuda de "reverentia" entre esposos, como expresión necesaria de la intimidad del lazo conyugal.

Estos son los rastós esenciales de una evolución en la disciplina jurídica del gobierno de la familia, que sé ha verificado hasta el presente de una manera racional y cuyo desarrollo sería deseable, de acuerdo en todo con la doctrina de la Iqlesia.

V.--Refomcs deztructoros del gobierno de la familia.

Veamos como se pretendería, por el contrario, instituir la igualdad en el gobierno de la familia, igualdad que, como lo hemos dicho, constituye un simple "idolum", sin ninguna justificación frente a la necesidad de un reparto orgánico de competencias entre los esposos y sin ninguna. relación con las verdaderas necesidades de la familia para el cumplimiento de su tarec insusticuible en la sociscicd.

El marido deja de ser el jefe de la familia y toda resolución debe adoptarse de común acuerdo por los esposos. La selección del domicilio común, si los esposos no llegan a un acuerdo, se transforma en asunto judicial; el tribunal puede autorizar al cónyuge $\alpha$ vivir en un domicilio distinto. Por otra parte, el cónyuge queda en libertad de escoger su profesión, salvo si el tribunal se lo impide en interés de la familia. Los esposos se comprometen recíproca y solidariamente a cuinplir con los deberes inherentes al matrimonio y el poder doméstico se convierte en recíproco. La comunidad conyugal legal de bienes se reduce a los gonanciales, con una modificación de los poderes respectivos de los esposos, inspirceder en el mismo principio de igualdad.

No solamente la autoridad sobre los hijos comprende a cada uno de les padres, sinó cue solo puede ser ejercidr conjuntamente por cinbos. Bl cacverdo se supone, salvo cposición frente a terceros. El conflicto puede planteoree por uno de Ios cónyuges, aún de manera preventiva, y llevada cnte el juez que deberá resciverlo.

Estos son los principios en los que estón inspirados los proyectos de reforma franceses a los ciue nos hemos referido.

En Alemania también, como en numerosos países, la igualdad absoluta del marido y de la mujer se plantea, y se rechaza el mismo con. cepto orgánico de la familia, con reparto de las funciones. Se reclama, de manera especial, la derogación del artículo 1354 del Código civil, que ciribuye al marido un poder decisorio; es por eso que todo asunio familiar imporiante, sobre el cual no se logra un acuerdo, no llega a su término. Se pide tombién la derogación del art. 1356 que fija el deber fur- 
damental de la mujer de ocuparse de la economía doméstica, con el fin de que ésta pueda dedicarse sin trabas a una actividad profesional; la supresión del deber especial de ayuda del marido debería también; sin duda, servir a esta finalidad. Conviene anotar que en Alemania se ha previsto como próxima, la dación de un estatuto legal de las alocaciones familiares.

Estas especificaciones de!. principio de igualdad justifican suficientemente, según me parece, la afirmación hecha al principio, a saber que su introducción en las legislaciones sería el signo que anunciaría la destrucción de la familia. De hecho, es vano suponer, en el desorden actual de las costumbres al cual nos referiremos más lejos, que la bomba colocada por la ley bajo la institución de la familia no estallará y que la simiente de la discordia no producirá sus frutos, en muchos, en demasiados casos.

Como lo veremos a continuación, de lo que se quejan hoy día, no es tanto del exceso, sinó de la falta de ejercicio de las autoridades familiares, y sobre todo de la autoridad de los padres: en estas condiciones, nadie cumpliró con los deberes indispensables a la prosperidad y a la existencia misma de la familia cada vez que, ya sea por capricho, ligereza, o rencor de uno de ellos, faltará el acuerdo de los esposos. La familia quedará paralizada y desaparecerá, por lo menos de la manera como la entendemos. Creer que la familia podrá progresar por medio de medidas dictadas por el juez u otra autoridad pública, es una ilusión tan ingenua que no se llega aún a comprender cómo puede concebirse entre los que no desean la destrucción de la formilia y, con la familia, la misma scciedad, en su organización actual.

Ademós unc intervención normal y determinanie de la autoridad estatal en el gobierno de la fomilia, -que es lo que se lograría con la nivelación de las posiciones de los esposos, - no quedaría limitada a la ayuda $\mathrm{y}$ al apoyo a la institución familiar, como podemos admitirio y desearlo. Colocaría a la familia a merced del Estado, contra el reconocimiento de los derechos de la familia como sociedad natural basada en el matrimonio la que, si se expresa por estas palabras en la Constitución italiana (Art. 29) se halla formulada en términos equivalentes en otras Cons. tituciones modernas.

A propósito de la Constitución italiana, es cierto que la mencionada disposición establece que el matrimonio se halla "basado en la igualdad moral y jurídica de los esposos", pero agrega "dentro de los límites señalados por la ley para garantizar la unión familiar": es precisamente el principio establecido por la doctrina de la Iglesia, especialmente por las fuertes, suaves e inolvidables palabras del "Casti Connubi", y el que también hemos tratado de defender aquí.

\section{VI.-Contenido de la autoridad marital.}

Examinaremos ahora algunos elementos de la autoridad marital y paterna, de interés particular, principalmente para nosotros, juristas católicos, ya que pienso que un repertorio de la legislación sobre este punto no sería necesario. 
Ya se ha hablado de la naturaleza y de los límites de las dos autoridades, y de la coordinación de las competencias de ambos esposos en sus relaciones entre ellos $y$ con sus hijos.

¿Existe todavía un poder de corrección del esposo sobre la mujer, pernitiéndole ejercer legítimamente un "vis modica" sobre ella? Aún cuando algunos relatores lo han afirmado, sacondo argumentos de leyes pencles que reprimen como un delito el abuso de los medios de corrección solve personas sometidas a una autoridad familiar, lo excluiremos para todas las legislaciones de las cuales ha desaparecido o en las que no figura $\in \mathrm{l}$ deber de obediencia de la mujer. Entonces el deber de protección del marido, allí donde existe, adquiere también un nuevo aspecto; Y lc autoridad marital afecta más genéricamente la persona de la mujer. La sujeción de la mujer se halla limitada a las prerrogativas específicamente y positivamente atribuídas al marido por la ley. La misma palabra "autoridad" parece más propia que la de "poder" para expresar esta situación.

Por la misma razón, no podremos admitir, teniendo en cuenta el silencio de la ley, un control del marido sobre las convicciones, sobre las relaciones y sobre la correspondencia de la mujer, lo que, por lo demás está de acuerdo con el respeto que se debe a la persona de la mujer.

La situación es distinta en cuanto se refiere a la selección de una profesión por la mujer. Con la abolición de la cutoridad marital, ha sucedido en algunos países, como en Italia, según se ha dicho, que el control del marido ha experimentado una disminución en lo que se refiere $\alpha$ las actividades extra-domésticas ejercidas por su esposa, principalmente en cuanto $\alpha$ las catividades profesionales separadas, (trabajo subordinado, profesiones liberales, comercio), ya que pueden ser incompatibles, en la realidad, con los deberes domésticos de la mujer. Aquí un control del marido, como jefe de la familia, se impone, preventivamente (autorización) - a posteriori (defensa, denuncia del contrato de trabajo), aún moderada con la intervención del juez, de manera a impedir todo abuso. Este control es muy necesario ya que se ha extendido la costumbre de las mujeres casadas de ejercer actividades profesionales.

El código alemón (art. 1358), los códigos holandés (art. 168) y suizo (art. 1673), el código francés en su texto actual (art. 223), entre otros, han previsto, bajo diferentes formas, el control del marido sobre el desempeño por su esposa de una profesión fuera del hogar.

Que la mujer deba disponer libremente de los bienes adquiridos gracias a su actividad profesional y particularmente de los que le son indispensables, esto se comprende. Lo que no se comprende, y lo que fué justamente materia de crítica, es que las obligaciones adquiridas por la mujer mediante su profesión se hallen también garantizadas por los bienes del esposo y los de la comunidad, como sucede en Francia (art. 226 del Código).

Como consecúencia de su calidad de jefe de la familia, el deber de sostenerla pesa principalmente sobre el marido, aún cuando la mujer está obligada a contribuir con él a los gastos del matrimonio. A este deber se agrega recíprocamente la posición preeminente, bajo diferentes formas, 
hecha al marido en cuanto a los bienes matrimonicles. La propuesta tendiente a suprimir el deber del marido de sostener a la familia, al mismo tiempo que la supresión de su situación de jefe de la misma no deja por lo tanto de ser incoherente. Sin embargo, muy distintas son las necesidades de la familia, y solo puede ponerse en evidencia la oportunidad del rópido procedimiento introducido por ciertos países con el fin de permitir o ia mujer, principamente tratándose de familias obreras, desconta: las sumas necescrias del salario del marido para el mantenimiento de la familia; on cuanto al código suizo, autoriza ademós al juez, cuando el marido no cumple con sus deberes familiares, a ordenar a los deudores de los esposos a efectuar sus pagos a la mujer (art. 171).

Los esposos deben principalmente ser iguales en el deber de fidelidad; ahora bien, como juristas católicos, no podemos sinó lamentar que algunas legislaciones del tipo latino -Italia y España, por ejemplomantengan para la separación legal de los esposos una distinción entre la infidelidad del marido que, como no se ignora, debe ser más grave, Y la infidelidad de la mujer, distinción que realmente no tiene verdadera justificación moral.

\section{VII.-Contenido de la patria potestad.}

La patria potestad comprende un poder de dirección, un poder de educación $y$ de vigilancia sobre la persona del hijo, así como un poder de corrección: poderes que corresponden a otras tantas funciones, atribuídas generalmente al espaso que está en ejercicio de la patria potestad, o a ambos cuando se trata de poderes que solo pueden ejercerse en común.

La existencia del poder de corrección no puede ponerse en duda, porque la patria potestad, a diferencia de la autoridad marital, produce una sujeción general del hijo menor, reforzada con el deber de obediencia o de respeto hacia los padres, que muchas legislaciones conservan de manera oportuna. Algunas leyes, el código suizo, por ejemplo, (art. 278), mencionan sin embargo, de manera directa $Y$ específica, el poder de corrección.

En su forma más rudimentaria, la corrección supone un castigo corporal. Dispone de muchos medios para ello y los mejora cada vez más; tiende a adaptarse al fin que se persigue, y que es el de reeducar. Las leyes señalan la gran variedad de medios, $y$, si algunas, ordenan todavía el encarcelamiento del menor bastando que lo solicite el padre a la autoridad, otras, como en Froncia, dejan al Juez de menores, cuya intervención en estos casos es muy apropiada, escoger entre las diferentes me. didas de educación que convienen para salvar a estos menores en peligro.

La desheredación es una sanción admitida también por algunas leyes: esta consiste en privar a los hijos de la cuota hereditcria que les corresponde.

\section{VIII.-Educación de los hijos.}

La educación de los hijos, fin principal del matrimonio, constituye la más importante manifestación del poder de dirección de los padres. 
En su concepto amplio, la educación comprende todas las clases de formación y de instrucción moral, intelectual y física de los hijos. También están comprendidas la enseñanza y la orientación profesional. El Código zuizo los comprende de manera específica, pero exige que se tenga en cuenta, en cuanto sea posible, las fuerzas, aptitudes y deseos del menor (art. 276) En Alemania, existe un servicio oficial de orientación profesional que her resultodo muy útil, respetándose, sin embargo, el poder de decisión del padre.

El capítulo de la educación religiosa es especialmente importante, por sus relaciones con la libertad de conciencia y la libertad religiosa, generalmente reconociders por les Constituciones vigentes.

Digamos inmediatamente que la educación religiosa se coloca en el primerísimo lugar en el poder de educación de quien ejerce la patria potez̃ad. Las libertades mencionadas anteriormente no podrían ser citadas para privar a los padres de la educación religiosa; de la misma manera esas libertades excluyen que se pueda considerar $\alpha$ los padres como también obligados a proporcionar la educación zeligiosa.

El código civil suizo atribuye específicamente a los padres la disposición sobre la educación religiosa del menor, proclamando la nulidad de toda convención limitativa y permitiendo al menor que haya cumplido 16 años, escoger su religión.

En las legislariones donde no existen reglas al respecto, se considera que la disposición referente a la educación religiosa del niño corresponde al cónyuge o a los padres que ejercen la patria potestad, mientras ésta subsista.

\section{IX.-Administración y goce de los bienes de los hijos.}

En general, pero ésto no constituye una regla fija, la administración de los bienes que pertenecen a los hijos menores está ligxda a la patria potestad, y va acompañada de su goce legal. En algunas legislaciones, como la francesa (arts. 389-390), la administración cambia de rubro: está sometida a la disciplina más controlada de la tutela, cuando el matrimonio se disuelve por muerte de uno de los esposos; pero ésto no sucede en caso de divorcio o de separación de cuerpos; sin embargo, en este caso el control de hecho de parte del otro cónyuge se muestra ineficaz y so puede deplorar que entonces no se establezca una tutela.

En lo que se refiere al control sobre la administración de los bienes de los mencres, notemos que varias legislaciones encomiendan tareas importantes a los Consejos de familia y de tutela. Otras legislaciones, por el contrario, los han suprimido, principalmente por el hecho de ser la expresión de un momento histórico sobrepasado, la de la importancia de la familia "communi iure", y también porque se han revelado poco aptos a la función que se les había encomendado. Se les ha reemplazado con organismos estatales; en Suiza, por ejemplo, el código confía la protección del derecho público a la autoridad tutelar, revestida de poderes extensos y elásticos con relación a la patria potestad (arts. 283, 284); en Italia, el código, vigente en este aspecto desde 1939, ha creado un juzgado tutelar, 
dotado de múltiples funciones de vigilancia y de control (arts. 337, 334).

Entre los bienes sustraídos al goce legal y a veces también a la adminisiración, se hallan generalmente los bienes adquiridos por el menor merced a su actividad profesional. En algunas legislaciones, como. la holandesa, el goce legal desaparece cuando los hijos viven fuera de la casa paterna, lo que tiene como consecuencia lamentable ei clejamiento de los hijos obreros del hogar de la familia.

A propósito de la actividad profesional de los menores, la cuestión consiste en saber si corresponde a las perrogativas del poder de administración de los padres obligarlos a una actividad determinada como. por lo demás, a toda actividad en general. Allí donde la ley no dispone atra cosa, la respuesta debe, según nosotros, ser afirmativa, sin que, naturalmente, el menor pueda verse, sin embargo, obligado positivamente por los padres. Señalemos, al respecto, la oportunidad, en interés de la familia y de terceros, del principio, que va haciéndose camino en las legislacio nes, y que consiste, por ejemplo, en anticipar a los 18 años la capacidad del menor para ciertos actos jurídicos, especialmente para el contrato de trabajo, y a reclamar, cún antes de esta edad, el consentimiento del menor, para ciertos actos firmados en su nombre por sus padres.

El menor, incapaz de actuar por sí mismo, puede más tarde, desde el instante que posee discernimiento, actuar a nombre de sus padres $y$ obligarlos con su consentimiento, ayudando, a su vez, a la familia.

\section{$\mathrm{X}$ - -Fin $\mathrm{Y}$ modificación de la patria potestad.}

En general, la patria postestad termina con la mayoría de los hijos, veintiun años, o al ser éstos emancipados, lo que no puede efectuarse antes de los diociocho años, a menos que se realice legalmente por el matrimonio. Pero la patria potestad también puede cesar por haberla perdido los padres por causa de abusos o abandono, con posibilidad de recuperarla al desaparecer el motivo, o como consecuencia de condenas penales determinadas; con motivo de otras condenas penales, puede ser temporalmente suspendida; puede ser limitada $y$ modificada de manera diferente según las leyes, y según la necesidad, con una amplitud que conviene perfectamente a la importancia de la función y a la diversidad de los casos.

\section{XI.-Las costumbres en el gobiemo de la familia y la opinión pública.}

Según los informes nacionales, las costumbres actuales de la familia no son dignas de la civilización cristiona en la mayoría de los países. Solamente el informe de España, entre lo que nos han llegado, nos presenta un cuadro consolador de la vida familiar, aunque con algunas reservas... Los otros informes denuncion unánimemente graves preocupaciones. Las preocupaciones no se refieren $\alpha$ abusos del marido al ejercer la autoridad marital o de los padres en el ejercicio de la patría potestad, sinó, por el contrario, a una desgraciada falta de autoridad. 
Parece que una fuerza centrífuga maléfica aleja de la familia al maricio y a la mujer, a los padres y a los hijos.

Los daños producidos por la llamada prensa libre, el teairo y principalmente el cinema - convertido en maestro de la perversión al alcance de todos- son demasiado conocidos y demasiado lamentados, para que sea menester extendernos sobre este asunto.

La más grave dificultad para la familia ze encuentre, sin embargo, en el abandono progresivo por la mujer de sus deberes familiares, para dedicarse a sus ocupaciones personales $\mathrm{Y}$, principalmente, profesionales... Lac doctrina de la Iglesia, siempre moderada y comprensiva, no condena ni prohibe la actividad profesional de la mujer casada; esta corresponde muchas veces a una imperiosa necesidad, pero hace notar que una emancipación mal entendida de la mujer no puede sinó dar lugar a la "perversión de toda la familia, por el hecho que el esposo queda privado de su mujer, los hijos de su madre, la casa y toda la familia de su vigilancia". Por eso la Iglesia exige que "el orden esencial de la sociedad doméstica permanezca intacto, como el que fué creado por una sabiduría mós elevada que la sabiduría humana, es decir la divina, y que no puede ser modificado por leyes públicas o deseos particulares". (Casti Connubi).

Pensamos, por consiguiente, que de este Congreso debe salir una invitación dirigida a las mujeres y principalmente a las mujeres católicas, una invitación serena y firme, exhortándolas a no desertar jamós, y por nin. gún motivo, su puesto de esposa y de madre, ya que la salvaguardia de la familia y de la misma sociedad depende de esto: con el deseo que se tomen todas las preccuciones, que se realicen todos los scrrificios para crear las condiciones necesarias al retorno de la mujer al hogar familiar.

Se dice que la doctrina de la Iglesia es generalmente más o menos conocida, pero lo que es más doloroso, es que no se practique, aún cuando el decaimiento de las costumbres sea menos notorio en las familias católicas.

La opinión pública, influenciada como lo está por los factores que hemos señalado, refleja las costumbres actuales y aún a veces se anticipa a ellas. La aplicación integral del principio mal entendido de igualdad entre los esposos, cuyos resultados hemos visto, hará lo demás.

La situación es particularmente grave en Alemania, como consecuencia de la guerra y de las situaciones que ha creado.

Solamente en el Líbano, bajo la influencia del derecho musulmán, y en el Perú, gracias a la modernización de la disciplina legal, se señala de parte del padre un empleo a la vez firme y bien entendido de su cutoridad sobre la familia: con este motivo, hagamos notar que el estatuto personal del matrimonio de los católicos libaneses se halla directamente inspirado en la doctrina de la Iglesia.

El peligro que corre actualmente la autoridad de los padres es aún más grave, principalmente frente a una juventud desorientada como la que ha vivido las tristes experiencias de las calamidades producidas por la guerra. Son sobre todo los padres que llevan y que llevarán la responsabilidad de este decaimiento de las costumbres: provocan a sus hijos ad iracundum, no ciertamente por su excesiva severidad, sino, por el contra- 
rio, debido "al relajamiento ya muy extendido de la disciplina formiliar. que favorece en los adolescentes las pasiones indómitas". (Divini illius magistri, 31 de diciembre de 1929). Pero volvamos al tema que estábamos trotando.

E! debilitamiento de las autoridades familiares y especialmente de 16: patria potestad, hace que intervengan las instituciones estatales y que extiendan su acción a la familia legítima: realizan una obra que se hace necesaria y a veces útil para la salvaguardia de la familia, pero pueden comprometer el delicado equilibrio entre el Estado y la familia en la defensa de sus intereses.

XII. - Intervención del Estado en el gobierno de la familia. Neturaleza y límites.

De esta manera hemos llegado a ocuparnos del último $\mathrm{y}$, para nosotros, tal vez el más importante argumento, la intervención del Estado en el gobierno de la familia.

La doctrina de la Iglesia sobre esta materia no deja duda alguna. La intervención del Estado es posible, diríamos aún es necesaria, debido a la naturaleza imperfecta de la sociedad familiar, que no encuentra en sí todos los medios apropiados a la protección de sus intereses; sin embargo, esta intervención debe mantener su carácter de auxiliar, sin tratar de sustituirse a la familia en las funciones que ésta puede y debe realizar.

Si la intervención del Estado, y mós específicamente, la del juez, se hace sentir cada vez más, esto se debe a la transformación en la cutoridad familiar que se ha realizado y que está realizóndose. Bien se comprende cómo liega a producirse la posibilidad de nuevas controversias que deben ser resueltcss por el juez, a medida que, de absoluta, la patria potestad se convierte en funcional, y a medida que un control o una participación es atribuída a la mujer al lado del marido.

Deberes de vigilancia y de control corresponden al Estado, y más particularmente $\alpha$ la autoridad administrativa $\mathrm{y}$ judicial, en cuanto al gobierno de la familia $y$, especialmente, sobre la autoridad patema. En varios países, se están creando con este fin juzgados especializados.

El Estado asume, por fin, funciones de administración activa por medio de sus órganos normales o de instituciones especiales, en el aspecto csistencial y educacional.

En cuanto a la intervención del Estado en el gobierno de la familia se presentan con razón, dos pedidos: que, en primer lugar la intervención del Estado respete $\mathrm{y}$ asegure, al móximo, el ejercicio de las autoridades y de las funciones dentro del marco familiar, favoreciendo la unidad de la familia; que, a continuación, las competencias de los órganos del Estado sean repartidqs racionalmente dentro del respeto de los principios de la libertad, solicitando que las autoridades y las instituciones administrativas, por una parte, y la autoridad judicial, por otra, desempeñen un papel conforme con la naturaleza institucional de la familia. Toda limita- 
ción de la autoridad y de los derechos familiares, toda imposición de sanciones deberían reservarse a la autoridad judicial.

La obra asistencial del Estado, aun referente a las familias, es floreciente en todas partes, ya sea debido a la legislación familiar, que se manifiesta bajo diferentes formas, y principalmente por medio de las integraciones de los salarios (alocaciones familiares) y de las prestaciones de previsiones obligatorias en función de las cargas familiares efectivamente soportadas, ya sea por medio de la utilización progresiva de las asistentas sociales, cuya aparición y aumento representan uno de los aspectos más significativos de la evolución de la institución familiar, por más complejas que resulten las razones del éxito de este nuevo elemento auxiliar de la familia.

Después de haber subrayado el gran beneficio que puede lograr la familia de esta amplia acción protectora del Estado, no se puede, sin embargo, silenciar el peligro que esa misma acción, que constituye sin duda, como se ha dicho. uno de los resultados del debilitamiento de la fornilia misma, se convierta en la causa que lo empeore.

A esta amplia acción exterior de asistencia familiar, la Iglesia participa oportunamente por medio de su clero $Y$ sus instituciones especiales y $\propto$ veces modernas, principalmente en ciertos países

El Estado aplica sanciones penales a la violación de los deberes de asistencia familiar, castigando también el abandono material y moral de la familia. Solamente en alqunos Estados, como el Perú y Holanda donde, sin embargo, existe un proyecto, el abandono de la familia no constituye un delito. Pero, también en este aspecto, se exige del juez una extrema prudencia con el fin de que salve lo que aún pueda salvarse y para çue el remedio no resulte peor que el daño.

Las esferas de competencia respectivas de la familia, del Estado $y$ je la Iglesia en la educación, en el seno de la cual comprendemos, como se ha dicho, toda clase de formación y de instrucción de la juventud, han sido determinadas con claridad y precisión por Ia Encíclica Divini Illius Magistri, que sigue siendo la Carta fundamental en este asunto.

$\mathrm{Y}$ aún, $\mathrm{Y}$ principalmente, diríamos, en la educación, la Iglesia ha desempeñado y desempeña su misión para la salvación eterna de los hombres, $y$ lo hace ahora en ciertos lugares, en los sectores más modernos, como la orientación profesional de los jóvenes.

El Estado, salvo cuando trata abiertamente de sustraer los hijos a Ias familias, con el fin de inculcarles un concepto negativo de todos los valores espirituales, repitiendo, como dice la Encíclica: "un verdadero y más horrendo masacre de los inocentes", se declara, en las Constituciones modernas, generalmente respetuoso de la libertad de la escuela y de la enseñanza.

Esta libertad es todavía suficiente para que los derechos intangibles de la Iglesia y de la familia en la educación puedan ejercerse, aún cuando no se reconozca a la Iglesia, salvo en ciertos Estados, como España 
después del reciente Concordato, la primacía del magisterio que le es: propio.

Pero es cierto que los reglamentos escolares tienden al monopolio de la educación, lo que es del todo inadmisible.

\section{XIII.-Conclusión.}

Liegado al final de mi informe, creo haber delineado un cuadro, amplio por el tema, indicando solamente sus grandes rasgos. Frente $\alpha$ una masa imponente de casos, he creído limitarme a lo esencial y a lo general. Dios quiera que haya logrado cumplir, aunque débilmente, con la tarea que me ha sido encomendada.

He deseado permanecer fiel al espíritu dentro del cual lor encuesta, que ha precedido este informe, ha sido organizada y realizada.

Este informe, basóndose en las instrucciones, sólo pretende ofrecer elementos para la discusión y las resoluciones de este Congreso. 